\title{
The Theory of Human Relatedness as a Potential Underlying Causative Mechanism in Nursing Student Placement Experiences: A UK-Based Critical Realist Study
}

\author{
Phil Coleman* \\ School of Health, Wellbeing \& Social Care, Faculty of Wellbeing, Education \& Language \\ Studies, The Open University, Walton Hall, Milton Keynes, MK7 6AA, United Kingdom
}

Received: 8 July 2021, Accepted: 31 January 2022

\begin{abstract}
Context: This study, underpinned by Critical Realism, re-analysed interview data acquired to examine the views and experiences of four stakeholder groups involved in the delivery of employer-sponsored pre-registration nursing programmes offered by a UK university in which all students already held an appointment as a non-registrant carer and who completed their placements within a block or integrated practicum framework. The re-analysis focused on the extent to which this interview data aligned with the key propositions of the Theory of Human Relatedness and therefore whether this theory, congruent with assertions based on the results of an earlier realist synthesis, might provide a causative explanation of factors affecting nursing student placement experiences.

Methods: Semi-structured, digitally recorded and professionally transcribed interviews, each lasting approximately 30 minutes, were held with a purposive sample of 37, predominantly female, respondents in 4 stakeholder groups involved in employer-sponsored pre-registration nursing programmes. These stakeholder groups were students, employers, mentors, and practice tutors and were associated with programme provision within twelve healthcare organisations in northern England.
\end{abstract}

${ }^{*}$ Corresponding author: phil.coleman@open.ac.uk 
Results: Although more modest in some areas, data provides support for every key proposition identified within the Theory of Human Relatedness; suggesting this theory may closely reflect the criteria that stakeholders implicitly employ to evaluate placement models. More respondents in all groups described the block practicum model in ways that suggest it is best able to promote a sense of connectedness, belonging and synchrony for learners. In contrast, an integrated placement design was portrayed in terms that implied it may increase the risk of disconnectedness but might also be more likely to promote reciprocity. Insufficient data was available to identify the perceived effect of either practicum design in respect of enmeshment, parallelism, and mutuality.

Conclusion: The results of this research suggest that a block placement may foster more positive relatedness experiences for students and other stakeholders within nursing programmes. Moreover, the extent to which a practicum framework is perceived to promote connectedness, belonging, reciprocity and mutuality, to minimise disconnectedness and enmeshment and to reduce the need for parallelism may underpin stakeholder appraisal of the two practicum frameworks. Little research regarding the effect of placement duration and intensity on student learning within pre-registration healthcare programmes or the application of the Theory of Human Relatedness to practicum experiences, however, has been undertaken to date and such investigation is complicated by inconsistent terminology to describe practicum designs. It is argued that further academic enquiry within both fields should be a priority for healthcare educators; not least because it may provide further insights into curriculum designs capable of reducing student attrition.

Keywords: Practicum, Placement, Duration, Intensity, Theory of Human Relatedness, VET, Vocational Education and Training

\section{Introduction}

For many years it has been widely acknowledged that practice learning is a critical feature within pre-registration nurse education programmes (Anderson \& Kiger, 2008; Andrews et al., 2006; EL Mokadem \& EL-Sayed Ibraheem, 2017; Murray \& Williamson, 2009; Ntho et al., 2020; Price et al., 2011; Tastan et al., 2015). In the United Kingdom (UK), half of the learning hours within such programmes are assigned to practice-based education (Nursing \& Midwifery Council, 2018); an allocation common to the pre-registration nursing curricula of many other nations (Warne et al., 2010). Whilst "a significant volume of nursing research has focused on students experiences of clinical placements" (Andrews et al., 2005, p. 142), most of these studies only address the supervision and support offered to nursing students by clinicians and educators, ignoring the potential impact of placement duration and intensity on practice learning (Coleman, 2021a). Most importantly, no specific practicum framework 
has consistently been shown to be more effective in facilitating such learning (Bhagwat et al., 2018; Rohatinsky et al., 2017).

Whilst placement designs have a variety of titles, most display the characteristics of either a block or integrated model (Coleman, 2021b). The block model, also termed the "daily" (Bonello, 2001), "full-time" (Shiverick, 2012) or "uninterrupted" (Archer, 2016) approach, provides intense, immersive periods of clinical placement lasting weeks, or months, which are commonly unbroken by academic study (Levett-Jones \& Bourgeois, 2011). In contrast, the integrated model, also referred to as the "concurrent" (Guin, 2019), "continuous" (McKenna et al., 2013), "day release" (Institute for Employment Studies \& International Centre for Guidance Studies, 2019), "distributed" (Reinke, 2018), "integrative" (Rasheed, 2017), "interspersed" (Grenier, 2015), "non-block" (Rohatinsky et al., 2017), "part-time" (Sala-Hamrick, 2019), "protracted", (Boardman et al., 2019) or "weekly" placement (Sheepway et al., 2011), involves students having episodes of both practice learning and academic study during the same programme week and may therefore offer scope for greater integration of theory and practice (Uys \& Gwele, 2005).

In a systematic review of "school-based integrated teaching for vocational knowing in nursing related training", Christidis (2019, p. 19) reports that this topic is scarcely explored and, even globally, relevant research is sparse. Within the existing small body of international work examining the effect of block and integrated practicum models on the learning experiences of pre-registration healthcare students, neither model has so far been identified as predominantly preferable or more beneficial to clinical learning. Some investigations have identified greater value within block placements (Amertil et al., 2020; Coghill, 2018; Peters et al., 2013; Reinke, 2018; Sheepway et al., 2011), whilst others have concluded that exposure to integrated practicum experiences offer better practice learning opportunities (Boardman et al., 2019; Kevin et al., 2010; Ranse \& Grealish, 2007; Vanson \& Bidey, 2019) or that there is no demonstrable benefit to either design (Perry et al., 2016; Sheepway et al., 2014). Moreover, several studies suggest both frameworks have strengths and weaknesses, and that stakeholder preference may be affected by individual circumstances, including the amount of programme study the learner has completed (Birks et al., 2017; Rohatinsky et al., 2017; Rohatinsky et al., 2018).

Further research related to the use of these models in the context of other disciplines, for example social work, have been similarly inconclusive. Although Rock \& Ring (2010) found that, amongst other benefits, a block practicum offered students better opportunities to apply and practice their professional knowledge and skills and helped develop greater awareness of the culture of the service in which a placement occurred, work by Theriot et al. (2006) found no statistically significant difference in student performance between learners undertaking placements based on either practicum design. Moreover, several studies within the discipline 
have identified advantages and disadvantages to both block and concurrent [integrated] formats for field education (Curl \& Cary, 2014; Hunter \& Hollis, 2013).

Critical Realism has been described as "a particularly relevant philosophical framework on which to base investigations within socially embedded, complex, empowerment focused, practice-based fields such as nurse education" (Coleman, 2020, p. 203) and within nursing and wider healthcare research this approach to academic investigation is growing in popularity (Bakhshi et al., 2015; Terry, 2013; Parpio et al., 2013). Research underpinned by this philosophy strives to have emancipatory outcomes (Wise, 2019), takes a position within a debate (Edgley et al., 2016), makes pragmatic recommendations (Corry et al., 2018) and seeks to locate causative mechanisms to explain observed phenomena (Bygstad \& Munkvold, 2011).

The Theory of Human Relatedness (THR) proposed by Hagerty et al. (1993), which highlights the importance of an "individual's perception of the quality of the interface between that individual and any perceived external source", suggests individuals assign meaning to their relatedness experiences based upon their sense of self and "the concurrent level of comfort or discomfort associated with that involvement" (p. 292). In the last three decades there has been growing interest in the THR and it has been applied to various fields, including paediatric nursing (Betz, 2004), the treatment of alcohol dependency (Strobbe et al., 2012) and social processes associated with adolescent connectedness (Karcher \& Lee, 2002). A more recent focus, however, has been on its use in explaining the importance of features of relatedness to nursing student learning experiences within placements (Levett-Jones et al., 2009; PotterDunlop, 2017).

Indeed, it has been argued that "if a student nurse does not fit in and does not feel part of the team, this has the potential to hinder his or her learning and ability to progress from the theoretical elements of nurse education to the practical elements of nursing in the real world" (Vinales, 2015, p. 534). A realist synthesis of existing theories that might be operating as underlying causative mechanisms affecting the practicum encounters of nursing students recently concluded that the THR "may provide the most complete theoretical framework to explain student practicum experiences", since it appeared to account for the "broadest range of observed phenomena highlighted in research associated with nursing student conduct in a clinical setting" (Coleman, 2021b, p. 113). To test these assertions, interview data derived from a recent investigation exploring the influence of block and integrated placements on clinical experiences within employer-sponsored pre-registration nursing programmes (ESPRNPs) at a UK university (in which either practicum design may be selected by the student's employer sponsor but in which total practicum hours are identical) were re-examined in the context of the THR.

The application of both block and integrated placements within the ESPRNPs is atypical in the UK where, traditionally, most open-entry nursing degree programmes have been based on a block practicum design. Moreover, unlike most undergraduate nursing program- 
mes, all entrants to these ESPRNPs are non-registrant carers (NRCs) employed within organisations providing healthcare services who only need to have the support of their employer and to meet the minimum entry requirements of the Nursing \& Midwifery Council (the UK regulatory body) to apply for one of the programmes. Employer support is an entry condition because organisations are required to meet any necessary staff backfill costs associated with providing each student with 2300 hours of mandatory supernumerary practice learning and to arrange appropriate clinical placements and student support from mentors (recently re-termed practice assessors). In most conventional open-entry nursing degree programmes where students are not employees of the organisation, such backfill costs are inevitably absent and the university providing a nursing programme would normally plan all required placements.

The pre-entry experience of ESPRNP students in delivering nursing care, albeit in nonregistrant roles, means that most are mature learners who may possess a level of familiarity regarding healthcare provision which is commonly absent amongst younger nursing students on open-entry programmes offered by other universities. Nevertheless, ESPRNP students may, by virtue of their NRC experience, sometimes be assumed to have higher levels of clinical skill than is the reality. A blended learning approach is used for academic study within these ESPRNPs, and student retention and achievement rates are generally much higher than on similar open-entry programmes; perhaps because of the discipline-specific pre-entry knowledge and work experience learners on these programmes possess. The lower level of entry qualification and the fact that ESPRNP students may not have completed any accredited formal learning for some considerable time, however, means that many of them find academic study much more challenging than conventional open-entry nursing undergraduates.

Outside of their placements, students on these ESPRNPs continue with their work duties as NRCs within the organisation; hence learners receiving integrated placements undertake nursing student and NRC roles during the same week as well as academic study in respect of their ESPRNP. Those assigned a block practicum have periods in which they are either a nursing student on placement or an NRC but concurrently undertake their ESPRNP academic studies irrespective of their clinical activity. This investigation, underpinned by Critical Realism, seeks to address the following research question: To what extent does evidence from ESPRNP stakeholders regarding the use of block and integrated placements support the notion that principles within the THR may be causative features underpinning practice learning experiences and practicum design preferences? 


\section{Methods}

Semi-structured interviews were undertaken with 37 representatives of 4 stakeholder groups involved in block and integrated practicum models used on ESPRNPs leading to BSc (Hons) awards in nursing and entitlement to join the Nursing \& Midwifery Council register. Each interview lasted approximately 30 minutes, was digitally recorded, and involved concurrent member checking (Beuving \& de Vries, 2015). Respondents chose the time and location of their interview. Most interviews were undertaken face-to-face, but almost all those completed during 2020 took place virtually due to restrictions associated with the COVID-19 pandemic. Before their implementation, two academics discussed and agreed the interview schedules.

The 4 stakeholder groups, predominantly female (33), were students (12), employers (9), mentors (8) and practice tutors (8), all of whom worked within 12 healthcare organisations in northern England. Students were aged 21 years or older, studying either an adult physical health (8) or mental health (4) pre-registration nursing degree programme and had at least entered the second year of their studies and so already experienced several placements. The employers were National Health Service (NHS) Trust managers in services delivering either physical (7) or mental (2) healthcare who could select the student's placement model. Mentors were all qualified nurses working in either physical (5) or mental (3) healthcare organisations in which ESPRNP students were located and who assessed the learner's clinical knowledge and skills. Practice tutors were teaching staff employed by the university to monitor ESPRNP learner progress and support students/mentors during placements. The professional background of these practice tutors was in either physical (5) or mental health (3) nursing.

All invitations to participate were by email and non-respondents were sent a follow-up email 2 weeks later. Those who still failed to reply were assumed to have declined the invitation. The researcher, an academic at the university, undertook all interviews but had no direct involvement with the student's education and was not employed by any healthcare organisations involved in the study. This individual, however, acted as the line manager for several practice tutor respondents. The investigation was approved by the university's research ethics committee and written informed consent was secured from all participants. Purposive sampling was utilised in this study and audio recordings of the interviews were transcribed by an independent professional transcription service. Data analysis in relation to key principles within the THR focused on manifest rather than latent content (Graneheim \& Lundman, 2004). Evidence aligned to features of the THR were shared for consideration by 3 disinterested academics, although no changes were recommended in relation to the preliminary results. 


\section{Results}

The purpose of this study, namely, to determine whether interview data from the 4 stakeholder groups illustrates, and therefore potentially supports, key principles within the THR as causative mechanisms associated with practice learning experiences and practicum design preferences, means that the results are presented in relation to these principles. Wherever possible, examples are drawn equally from all stakeholder groups to facilitate fair dealing (Mays \& Pope 2000). Stakeholders are identified by their ESPRNP role; namely employer $[\mathrm{E}]$, mentor $[\mathrm{M}]$, practice tutor $[\mathrm{P}]$ or student $[\mathrm{S}]$ and a unique identification number. Respondent comments that may enable recognition of any organisations are replaced by generic descriptors, shown in brackets, and terms to facilitate comprehension are provided in the same way.

\subsection{Connectedness}

Within the THR, "connectedness" refers to interactions with other individuals, objects, or an environment that produce individual feelings of comfort, well-being, and a reduction in anxiety (Levett-Jones et al., 2009). Congruent with the concept of connectedness, several respondents recognised the need to ensure placement provision promoted student integration and accommodated the needs of the individual learner:

E9: "We are very aware that, although student nurses are supernumerary, they are expected to be part of a team"

P3: "It's about fitting the placement to the person"

Most respondents suggested a block model of practice learning was more likely to facilitate student experiences that promoted a sense of connectedness:

E8: [Better if students are] "able to immerse themselves in a four-week block, experience the shifts, experience how their mentor will work across that working week"

M8: "She [student] found it easier to comfortably slot herself into the team and just really know what was going on with the block placement"

P2: "They [students] say that they prefer to come, be a student on block and be a part of the team and be seen as a student and own that identity"

S5: "Being a student at the end of my four week block or whatever, I've very much made good relationships here" 
In contrast, the integrated model was seen as adversely affecting scope for connectedness:

M8: "If you were to do like an integrated placement with ward hours, it would be quite flaky really, you wouldn't be seeing as much of them" [ESPRNP students]

P4: "People [staff and patients] on the placement don't actually get much time with the students if they're only there for two days [integrated model], and I think that sometimes can have a negative impact on developing those relationships on placement"

\subsection{Disconnectedness}

The THR terms a lack of active involvement by an individual within a specific environment as "disconnectedness" and suggests this state may cause anxiety, distress, and reduced wellbeing (Hagerty \& Patusky, 2003). Several employer respondents in this study expressed concern that a lack of familiarity with ESPRNPs amongst staff located in placement settings may have adverse consequences for students on these programmes which might propagate disconnectedness:

E4: "The students lose confidence in their mentors as well if the mentors feel like 'oh this isn't what I'm used to, I don't know what I'm doing with this" [student]

E9: "They [ESPRNP students] are wearing, however, a different uniform to nursing students [from other universities] in their more, in previous, you know, and so first of all that makes them look a bit different, and people perhaps then start to think of them a bit differently"

Unfortunately, some ESPRNP students reported practicum experiences that had indeed contributed to a sense of disconnectedness:

S3: [Mentors have said] "you're not a proper student because you know what you're doing"

S6: "From day one they had me, it was written in black and white on the lovely mentor board, and I was written on there as a nursing apprentice [the individual was not an apprentice], which I asked them to change but they didn't"

S5: [During placements] "there's times where I've felt a little lonely"

The tension caused by being an ESPRNP student and an NRC was also acknowledged and could evoke a sense of disconnectedness during a placement:

M6: "Sometimes they [ESPRNP students] would like to support the nursing team when we're busy, when we're needing things done, but actually they're not allowed to do that" 
In most instances, respondents appeared to suggest that the risk of disconnectedness might be greater during integrated placements:

E4: "I think particularly for students who are only going in for two days a week [integrated practicum], they would probably be a bit lower down the priority list from a mentor's point of view. Because they don't know them as well, they're not as invested in them"

M4: "So they [ESPRNP students on an integrated placement] miss out maybe on the, they'll come back and say 'oh how's that man?' and they'll have died, so they've missed out that bit of continuity"

Nevertheless, one student suggested a block practicum could be equally problematic in respect of their NRC work:

S7: [With block placements] "I'm pulled out of that, and then put back in. So, it's starting again, at least for the first week to get back into how the routine goes. You carry over some skills, but not all of the everyday routine stuff"

\subsection{Parallelism}

Within the THR, "parallelism" refers to situations when a lack of involvement is experienced as comfortable and promotes a sense of well-being (Strobbe et al., 2012). Only limited examples which might illustrate this feature were evident within the interview data. $\mathrm{Ne}$ vertheless, several ESPRNP students noted their tendency to revert to their NRC role and independently deliver care in the absence of direction or guidance from placement staff. Moreover, most appeared at ease with such parallel working if they felt they were making a meaningful contribution to service provision within this setting. Their actions, however, were not always perceived positively by others:

S2: "Sometimes you can come onto the ward [placement] and it's kind of 'oh, you're an auxiliary [NRC], you know what you're doing'. So, you sometimes get left to your own devices"

S6: "I have been criticised for being on a ward and just disappearing and getting on with some jobs. Because that's what I've always done as a healthcare" [NRC]

S10: "I said oh, during one of the - one of my mentors, I said 'oh how am I doing?' She said, 'well actually I forget that you're here because you just get on and do it"'

Demonstration of behaviours which may be associated with parallelism did not appear to be affected by the practicum model to which the student was exposed. 


\subsection{Enmeshment}

The THR suggests that active involvement of an individual can sometimes generate discomfort, anxiety, and a lack of well-being. Such experiences are categorised as "enmeshment" (Potter-Dunlop, 2017). Both employers and ESPRNP students reported concerns that having concurrent status as an NRC could lead learners to feel embarrassed about the limits of their knowledge and be less assertive during a practicum:

E5: "Healthcare assistants [NRCs] who have been student nurses on the traditional programmes, they haven't wanted to admit that they don't know how to do something"

E9: "As healthcare assistants [NRCs], you know what your place is, you know what your role is and lots of healthcare assistants feel that their place is not to speak out because that's not the right thing"

S4: "I almost feel stupid for not knowing" [how to carry out a clinical procedure]

S10: "She [mentor] told me that if I didn't take this patient's blood pressure [despite the mentor not having determined her proficiency to do so] and anything happened to them it would be my fault"

One mentor suggested ESPRNP students may also be more likely to be assigned tasks of limited educational value during a placement and that their supernumerary status (although enshrined in UK law) may be perceived differently to that of open-entry nursing students:

M6: "They [ESPRNP students] may get given more mundane jobs which aren't really great for their learning'. Because they [ESPRNP students] are paid members of staff, they are always going to therefore be counted in some form of skill mix and numbers on the wards"

Indeed, it was even suggested that tension and animosity were sometimes evident between ESPRNP, open-entry students and clinical staff in a placement setting:

M2: "On some occasions members of staff, as well as other students from for example [names of three other universities], feel a sense of resentment maybe towards [ESPRNP students] ... in that they are paid as a health carer for two shifts of the week"

M6: "The [ESPRNP] students have sometimes said they [open-entry nursing students from three other universities] get treated differently because they are supernumerary and they're not getting paid"

S12: "Because when the staff find out you're still getting paid. The NAs [NRCs] are Band 2 [NHS salary scale], and they find out you're a student and you're earning a Band 3 wage, they're like 'well they can do more, they can do more work'" 


\subsection{Belonging}

Within the THR, "belonging" refers to those conditions which lead an individual to feel a positive, integral part of a process, activity, or environment (Hagerty et al., 1993). The importance of ESPRNP students having a sense of belonging within a practicum was highlighted by respondents in almost every stakeholder group and, commonly, a block practicum was deemed to best promote it:

E9: "I think it [a block placement] gives [the ESPRNP student] the impression of allowing more consistency: You're a fulltime member of staff for six weeks"

P1: "People [ESPRNP students] do definitely feel valued and they often say I felt part of the team. Now those tended to be, the ones I remember are people who've had a block placement"

S9: "I just feel like I'm a part of the team" [in a block practicum]

In contrast, placements based on the integrated model were perceived as adversely affecting the way ESPRNP students were perceived:

M8: "It just more feels like someone doing a bank shift [itinerant nursing staff input] with that [integrated placement], rather than getting that full learning experience from a ward shift perspective"

P2: "Because it was too bitty to not do it on block [placement], they [the employer] felt that they [ESPRNP students] would feel more a part of the team"

S6: "I did not appreciate being shouted at [by the ward manager], but I did understand her frustration. And she kept saying 'you've been here five weeks and I still haven't seen your portfolio' [competence record]. I hadn't, I've been there five shifts" [in the integrated model]

\subsection{Reciprocity}

Related to the concept of belonging, the THR describes "reciprocity" as an "individual's perception of an equitable alternating interchange with another person, object, group, or environment that is accompanied by a sense of complementarity" (Hagerty et al., 1993, p. 294). A key illustration of reciprocity in respect of ESPRNP student activity was the scope for such individuals to disseminate the learning they acquired in one setting to others in which they had a role:

E1: "So being able to share, they're [ESPRNP students] like little bees and pollinating everywhere"

M4: "I find that I learn from them [ESPRNP students] and then they learn from me" 
S11: [NRC workplace managers have] "said that they can see a massive difference in terms of sort of [my] competence and communication with the patients" [through their ESPRNP student role]

One student highlighted the importance they assigned to having a voice during a practicum and of both contributing to nursing care and being assisted to develop their nursing knowledge and skills:

S3: "They've [placement staff] been quite open with my suggestion". "I got stuck in straightaway with the nursing stuff. So, my first shift I was doing drug rounds, I was preparing IVs [intravenous infusions]. She was quizzing me on drugs. She [mentor] was explaining things to me, which was really good"

Interestingly, the potential for ESPRNP students to demonstrate reciprocity via disseminating their learning from different settings was largely seen as being enhanced by exposure to integrated placements:

M4: "To reflect on what they've [ESPRNP students] learned on the two days out of their normal practice and then they can take it back and integrate it in. And it makes you look at things with fresh eyes"

P5: "Students on the integrated model because it's longer they reflect more on the practices that they're doing, and they can think about where they are as a healthcare assistant [NRC]. And they start to integrate those changes in practices into their everyday" [NRC work]

\subsection{Mutuality}

In the context of the THR, "mutuality" describes situations in which a person believes they share a vision, goals, sentiments, or characteristics with others, but can also accept recognised differences between themselves and those with whom they interact (Haggerty et al., 1993). Evidence of mutuality within the study data was modest, although several nursing students highlighted the way in which they perceived some registrant clinicians with whom they worked as highly desirable role models:

S1: "Your mentor can be a good role model for you, [so you] just [want] to do what she does or what he does"

S5: "Then there's certain aspects [nurses] who are complete inspirations and [you think] 'I want to be that practitioner"'

Student expressions of mutuality did not appear to be affected by the model of practice learning underpinning their placements. 


\subsection{Synchrony}

The THR suggests that "synchrony" occurs when a person's experiences are congruent with his or her internal psychological, social, spiritual and/or physiological rhythms and their interaction with the external world (Haggerty et al., 1993). The tension and dissonance associated with moving between the NRC and ESPRNP student roles, not least in respect of appropriate conduct and skills application, was recognised by virtually all respondents in the 4 stakeholder groups. Which practicum model best contributed to synchrony, however, was a matter of greater debate. Some respondents believed that an integrated placement reduced transitional problems:

M2: [With integrated placements] "the students felt a sense of security maybe that they still kept their healthcare $[\mathrm{NRC}]$ role, but had one shift a week where they could concentrate on being the student nurse"

P6: "If you are doing say two days a week [integrated practicum], to have [it provides] a little bit of time to reflect, because they're not there every day. So, if you've learned something new, or been in a new situation, when you then go back for a few days into your comfort zone so to speak, where you've worked for a long period of time, it gives you that little bit of time to think"

Since most ESPRNP students were mature learners and therefore had other significant commitments beyond both their course learning activities and NRC duties, the integrated model was also described as more accommodating in respect of wider commitments:

M3: "It's the first time I've come across anybody [nursing student] doing the training this way [with an integrated placement]. So, I thought 'oh it's a bit odd' at first, then actually as I got to know her I realised that it actually really suited her, but it also suited the department's needs as well"

S7: "I've got children to get to school and having two days a week [integrated placement] would be much better personally than having the full block placement and having to cover four weeks, six weeks, ten weeks of childcare, whereas two days a week my mum and dad could handle that"

S12: "From a financial perspective [if] I was full-time [block] on placement, I'd lose out on enhancements" [additional NRC unsocial hours payments]

Other respondents, however, suggested a block practicum reduced the difficulties related to fulfilling a nursing student and NRC role by enabling periods of uninterrupted clinical learning and helping the NRC role of the ESPRNP student to be set aside for longer periods:

E9: [A block model was chosen] "to stop any dis-settlement from a mentor's point of view which may then impact on the student or their learning experiences" 
M8: "They [ESPRNP students] voiced that they preferred the block method, they found it easier to, as I say, slot them self into the team and just how the ward ran really. It made them more comfortable"

P4: "Students who were on block placements found it easier, because what they then say to me was that during the time when they're on placement they don't actually have to think about their role as a healthcare assistant" [NRC]

S8: [In a block placement] "I wouldn't be torn between my role as an HCA or a support worker [NRC], and my role as a student as much"

\section{Discussion}

Analysis of interview responses from members of the 4 stakeholder groups against key features of the THR suggests this conceptual framework provides a useful theoretical explanation of the factors underpinning ESPRNP practicum perceptions and experiences. Indeed, every key structural element of the theory, namely "connectedness", "disconnectedness", "parallelism", "enmeshment", "belonging", "reciprocity", "mutuality", and "synchrony", was evidenced within the data. The number of responses supporting the influence of parallelism and mutuality, however, was more limited. This paucity of reported experiences reflecting parallelism may be attributable to stakeholders wishing to avoid any suggestion that such activity, which may be seen as professionally undesirable, might occur during a practicum. Although located outside this study, the researcher has since been advised of anecdotal accounts related to mental health pre-registration nursing students in physical care placements who have responded primarily to the psychological needs of patients in the setting due to an absence of clear supervision or direction from clinicians and yet found such work fulfilling, as well as learners identifying specific practitioners as influential role models with whom they feel an affinity; suggesting wider evidence of parallelism and mutuality may be available.

Critical Realist research commonly examines topics in which underlying structures and relationships may affect observed phenomena but for which it is impossible to prove a causeeffect relationship (Harper, 2011). Hence, investigations such as this study, commonly seek to establish the most probable explanation for empirical findings; an approach known as "retroduction" (Meyer \& Lunnay, 2013). Arguably, the alignment of stakeholder experiences and reflections upon ESPRNP student placements to the key features of the THR identified within this investigation suggests that these psychosocial variables may have as significant an impact on practicum model preference and the practice learning experiences of nursing students as, for example, the opportunities for clinical skills acquisition in a placement, the inter-relationship between classroom and work-based learning or the effect of concurrent 
nursing student employment - factors traditionally given far greater consideration in academic discussion related to placement organisation.

Essentially, the findings may suggest that stakeholders unknowingly base their evaluation of practicum models on criteria largely reflected within the key propositions of the THR. That is to say, what could determine an individual's perception of an effective placement framework more than structural considerations, is the extent to which it is tacitly perceived as promoting connectedness, belonging, reciprocity, mutuality, and synchrony and minimising disconnectedness and enmeshment as well as reducing the need for parallelism. Inevitably, the concurrent NRC role undertaken by ESPRNP students prevents the influence of the workplace in which a student is employed in their NRC role being clearly separated from their clinical placement experiences. Nevertheless, and still congruent with the THR, such employment may be a feature affecting an individual's appraisal of the extent to which a practicum is deemed to promote a positive sense of relatedness and mitigate against the risk of negative psychosocial experiences. The relatively recent introduction within some UK nations of new employment-based programmes enabling a learner to acquire a nursing degree and entitlement to join the NMC register, termed "Registered Nurse Degree Apprenticeships", has triggered an increased use of integrated placements by other universities and so these programmes may offer scope for wider examination of stakeholder perceptions regarding block and integrated practicum models.

Furthermore, it is interesting to speculate if an implicit negative stakeholder evaluation of a specific practicum model (based upon analysis congruent with the THR principles) may alone be sufficient to adversely affect a practice experience. In other words, whether merely perceiving a placement model as less effective in facilitating positive aspects of relatedness might impair the potential for successful student learning within any forthcoming clinical practicum structured upon the model of concern. Given the well-recognised influence other intrapersonal factors may have upon interpersonal relationships, such an effect cannot be readily dismissed. If this form of prejudice is indeed a potential risk, which seems plausible, then it is perhaps one best mitigated by pre-emptive interventions designed to change an unfavourable placement model perception; for example, via pre-placement preparation for nursing students akin to those interventions advocated in several earlier studies (Priest, 2005; Sherratt et al., 2013) but designed to meet alternative goals. Since concerns regarding a lack of high-quality practicum experiences for nursing students have now been expressed internationally for several decades (Barnett et al., 2008, Brown et al., 2011; Gale et al., 2016; Kaliyangile \& Ngoma, 2020; National Nursing \& Nursing Education Taskforce, 2006; Shearer \& Lasonen, 2018), it appears crucial to create conditions in which both models are perceived favourably if use of placement capacity is to be optimised.

It is acknowledged that the respondent sample (37) employed in this analysis was relatively modest and that the interviews from which evidence was obtained were originally structured 
to examine stakeholder views, encounters and learning in the context of block and integrated practicum models for ESPRNP students rather than examine the THR as a possible causative dimension of placement perceptions. Alternative questions designed specifically to probe features of the THR might therefore have generated more explicit responses but, since such data re-analysis was not originally planned, it could be argued that the transcriptions provide a more robust and objective evidence base and that support for the THR is strengthened by consideration of this theory having been avoided within the original research design. It is also acknowledged that the researcher was the line manager for several practice tutor respondents although, given that the topic is not value-laden and both practicum models were offered within the ESPRNPs provided by the university and without institutional preference, it seems less likely that any pre-existing relationships would have affected the responses given.

Overall, the results of this Critical Realist study highlight that more respondents in all groups describe the block practicum model in ways that suggest it is best able to promote a sense of connectedness, belonging and synchrony for learners. In contrast, an integrated placement design was portrayed in terms that implied it may increase the risk of disconnectedness but might also be more likely to promote reciprocity within the ESPRNP student experience. Insufficient data was available to identify the potential effect of either practicum design in respect of enmeshment, parallelism, and mutuality. Further analysis of primary and secondary data associated with nursing student placement experiences could enable additional scrutiny of the THR as a framework to explain the factors underpinning clinical learning experiences for a wider student population undertaking pre-registration healthcare programmes. Nevertheless, evidence to date already supports the assertion that nurse educators should give appropriate regard to the likely impact of features highlighted within the THR when arranging placements if these are to consistently be more positive learning experiences which enhance clinical competence and promote the wellbeing of nursing students.

\section{Conclusion}

In common with other psychosocial theories of learning and development, the THR maintains that the nature of an individual's involvement in an environment and the social relationships they form within it may have significant cognitive and emotional effects. Levels of self-confidence, comfort, anxiety, and a sense of wellbeing are therefore shaped by such activity. Clearly, placements may offer emotionally charged episodes of social, intra-disciplinary and inter-disciplinary interaction for students on any pre-registration healthcare programme and generate either positive opportunities for deep and meaningful learning or have negative consequences that may not only impair future professional development but cause some learners to disengage from their programme. One respondent in this study [P3] articulated her view that, during a placement, nursing students 'are there to learn, not to be a member 
of the team'. Both the THR and results from this study, however, would refute such a view; countering that effective practice learning and positive relatedness experiences, such as that derived from a student feeling a member of the service team within a practicum, are both inter-related and inseparable. Clearly, whilst other factors may also affect placement experiences, it is argued that there is now a need for greater consideration of the influence of the THR principles to such learning activities.

Although a larger body of work may be evident within other professional fields, the effect placement duration and intensity may have on the student experience is a seriously underresearched topic within nursing and other healthcare disciplines and is one complicated by inconsistent terminology to describe the same practicum design. Although there is "no central record of student nurse attrition in the UK and no standardised method of recording it" (Urwin et al., 2010, p. 203), it has been estimated that "the average attrition rate for student nurses in England is 20\%" (Boath et al., 2016, p. 81) and more recent research indicates that student attrition on pre-registration nursing programmes is as high as $50 \%$ in some UK universities (Buchan et al., 2019). It seems inconceivable that negative practicum experiences are not a potential contributory factor in student attrition from such courses. Given some existing evidence suggesting placement design may affect student wellbeing, but the lack of a comprehensive knowledge base associated with the influence of placement duration and intensity on practice learning, it is argued that further research to examine causative mechanisms in such experiences should be afforded a much higher priority within healthcare education than is currently the case.

\section{Acknowledgements}

I would like to convey my thanks to Prof. Gillian Vance, Prof. Liz Todd and Dr Bryan Burford at Newcastle University for their insightful observations and suggestions related to the design and implementation of this study.

\section{References}

Amertil, N., Ayitey, E., \& Kpongboe, D. (2020). Assessing the effects of clinical placement models on undergraduate nursing students in a private university in Ghana. International Journal of Health Science Research, 10(11), 188-197. https://www.ijhsr.org/IJHSR_Vol.10_Issue.11_Nov2020/ IJHSR_Abstract.026.html

Andrews, G., Brodie, D., Andrews, J., Hillan, E., Thomas, B., Wong, J., \& Rixon, L. (2006). Professional roles and communications in clinical placements: A qualitative study of nursing students' perceptions and some models for practice. International Journal of Nursing Studies, 43(7), 861-874. https:// doi.org/10.1016/j.ijnurstu.2005.11.008 
Andrews, G., Brodie, D., Andrews, J., Wong, J., \& Thomas, B. (2005). Place(ment) matters: Students' clinical experiences and their preferences for first employers. International Nursing Review, 52(2), 142-153. https://doi.org/10.1111/j.1466-7657.2005.00262.x

Anderson, E., \& Kiger, A. (2008). 'I felt like a real nurse' - student nurses out on their own. Nurse Education Today, 28, 443-449. https://doi.org/10.1016/j.nedt.2007.07.013

Archer, E. (2016). Engaging patient-centredness in an undergraduate medical curriculum. [Doctoral dissertation, Stellenbosch University]. https://scholar.sun.ac.za/handle/10019.1/100338

Bakhshi, M., Ranjbar, H., \& Heydari, A. (2015). Critical realism: An important philosophical perspective for nursing researches. Journal of Torbat Heydariyeh University of Medical Sciences, 3(3), 56-62. http://jms.thums.ac.ir/article-1-324-en.html

Barnett, T., Cross, M., Jacob, E., Shahwan-Akl, L., Welch, A., Caldwell, A., \& Berry, R. (2008). Building capacity for the clinical placement of nursing students. Collegian, 15(2), 55-61. https://doi. org/10.1016/j.colegn.2008.02.002

Betz, C. (2004). Relatedness. Journal of Pediatric Nursing, 19(4), 235-237. https://doi.org/10.1016/j. pedn.2004.06.002

Beuving, J., \& de Vries, G. (2015). Doing qualitative research. The craft of naturalistic inquiry. Amsterdam University Press.

Bhagwat, M., Hewetson, R., Jones, L., Hill, A., Nunn, J., Tosh, R., \& Cahill, L. (2018). Comparison of paired and single clinical placement models: A time-use analysis. International Journal of Language \& Communication Disorders, 53(3), 468-479. https://doi.org/10.1111/1460-6984.12360

Birks, M., Burkot, C., Bagley, T., Mills, J., \& Park, T. (2017). The impact of clinical placement model on learning in nursing: A descriptive exploratory study. Australian Journal of Advanced Nursing, 34(3), 16-23. https://www.ajan.com.au/archive/Vol34/Issue3/2Birks.pdf

Boath, E., Jinks, A., Thomas, N., Thompson, R., Evans, J., O'Connell, P., \& Taylor, L. (2016). Don't go with the 'FLO' - a student mobile texting service to enhance nursing student retention. Nurse Education Today, 45, 80-86. https://doi.org/10.1016/j.nedt.2016.06.019

Bonello, M. (2001). Perceptions of fieldwork education in Malta: Challenges and opportunities. Occupational Therapy International, 8(1), 17-33. https://doi.org/10.1002/oti.129

Boardman, G., Lawrence, K., \& Polacsek, M. (2019). Undergraduate student nurses' perspectives of an integrated clinical learning model in the mental health environment. International Journal of Mental Health Nursing, 28(1), 96-104. https://doi.org/10.1111/inm.12496

Brown, T., Williams, B., McKenna, L., Palermo, C., McCall, L., Roller, L., Hewitt, L., Molloy, L., Baird, M., \& Aldabah, L. (2011). Practice education learning environments: The mismatch between perceived and preferred expectations of undergraduate health science students. Nurse Education Today, 31(8), 22-28. https://doi.org/10.1016/j.nedt.2010.11.013

Buchan, J., Charlesworth, A., Gershlick, B., \& Seccombe, I. (2019). A critical moment: NHS staffing trends. retention and attrition. The Health Foundation.

Bygstad, B., \& Munkvold, B. (2011). In search of mechanisms. Conducting a critical realist data analysis [Paper presentation], Thirty Second International Conference on Information Systems, 4-7 December, AIS, Shanghai. https://aisel.aisnet.org/icis2011/proceedings/researchmethods/7/

Christidis, M. (2019). Integrated teaching for vocational knowing: A systematic review of research on nursing-related vocational education and training. Nordic Journal of Vocational Education and Training, 9(2), 19-50. https://doi.org/10.3384/njvet.2242-458X.199219 
Coghill, E. (2018). An evaluation of how trainee nursing associates (TNAs) balance being a 'worker' and a 'learner' in clinical practice: An early experience study. Part 1/2. British Journal of Healthcare Assistants, 12(6), 280-286. https://doi.org/10.12968/bjha.2018.12.6.280

Coleman, P. (2020). A Critical Realist review of practice learning experiences within pre-registration nursing programme. EAS Journal of Nursing and Midwifery, 2(6), 202-212.

Coleman, P. (2021a). "Yes, the type of student supervision matters, but what about the placement structure?" - a critical realist review of block and integrated practice learning models within preregistration nursing programmes. Journal of Nursing Education and Practice, 11(1), 39-50. https:// doi.org/10.5430/jnep.v11n1p39

Coleman, P. (2021b). A realist synthesis of potential underlying causative mechanisms related to the optimal design of a nursing student practicum. EAS Journal of Nursing and Midwifery, 3(3), 106117.

Corry, M., Porter, S., \& McKenna, H. (2018). The redundancy of positivism as a paradigm for nursing research. Nursing Philosophy, 20(1), 1-10. https://doi.org/10.1111/nup.12230

Curl, A., \& Cary, S. (2014). A program evaluation of block and concurrent practicum formats. Field Scholar, 4(2), 1-10. https://fieldeducator.simmons.edu/article/a-program-evaluation-of-blockand-concurrent-practicum-formats/

Edgley, A., Stickley, T., Timmons, S., \& Meal, A. (2016). Critical realist review: Exploring the real, beyond the empirical. Journal of Further and Higher Education, 40(3), 316-330. https://doi.org/10 .1080/0309877X.2014.953458

El Mokadem, N., \& Ibraheem, S. (2017). Nursing students' satisfaction with their clinical learning environments. American Journal of Nursing Research, 5(4), 104-108.

Gale, J., Ooms, A., Sharples, K., \& Marks-Maran, D. (2016). The experiences of student nurses on placements with practice nurses: A pilot study. Nurse Education in Practice, 16(1), 225-234. https:// doi.org/10.1016/j.nepr.2015.08.008

Graneheim, U., \& Lundman, B. (2004). Qualitative content analysis in nursing research: Concepts, procedures and measures to achieve trustworthiness. Nurse Education Today, 24(2), 105-112. https://doi.org/10.1016/j.nedt.2003.10.001

Grenier, M. L. (2015). Facilitators and barriers to learning in occupational therapy fieldwork education: Student perspectives. American Journal of Occupational Therapy, 69(2), 1-9. https://doi. org/10.5014/ajot.2015.015180

Guin, S. (2019). Field work supervision through open and distance learning: An Indian perspective. Asian Association of Open Universities Journal, 14(2), 107-121. https://www.emerald.com/insight/ content/doi/10.1108/AAOUJ-08-2019-0031/full/html

Hagerty, B., Lynch-Sauer, J., Patusky, K., \& Bouwsema, M. (1993). An emerging theory of human relatedness. Journal of Nursing Scholarship, 25(4), 291-296. https://doi.org/10.1111/j.1547-5069.1993. tb00262.x

Hagerty, B., \& Patusky, K. (2003). Reconceptualizing the nurse-patient relationship. Journal of Nursing Scholarship, 35(2), 145-150. https://doi.org/10.1111/j.1547-5069.2003.00145.x.

Harper, D. (2011). Choosing a qualitative research method. In D. Harper \& A. Thompson (eds.), Qualitative research methods in mental health and psychotherapy (pp. 83-98). Wiley-Blackwell.

Hunter, P., \& Hollis, C. (2013). Exploring international internships in social work education. Field Educator, 3(1), 1-19. https://fieldeducator.simmons.edu/article/exploring-international-internships-insocial-work-education/ 
Institute for Employment Studies \& International Centre for Guidance Studies. (2019). Evaluation of T level industry placement pilot: Route reports. Department for Education. https://www.employmentstudies.co.uk/resource/evaluation-t-level-industry-placement-pilot

Kaliyangile, B., \& Ngoma, M. (2020). Student nurse's clinical learning environment: Clinical teachers' perspective. Texila International Journal of Nursing, 6(1), 1-4. https://doi.org/10.21522/ TIJNR.2015.06.01.Art006

Karcher, M., \& Lee, Y. (2002). Connectedness among Taiwanese middle school students: A validation study of the Hemingway Measure of Adolescent Connectedness. Asia Pacific Education Review, 3(1), 92-114. https://eric.ed.gov/?id=EJ652000

Kevin, J., Callaghan, A., Driver, C., Ellis, J., \& Jacobs, B. (2010). A possible alternative model of clinical experience for student nurses. Journal for Nurses in Staff Development, 26(5), 5-9. https://doi. org/10.1097/NND.0b013e3181b1ba07

Levett-Jones, T., \& Bourgeois, S. (2011). The clinical placement. An essential guide for nursing students (2nd Ed.). Elsevier Australia.

Levett-Jones, T., Lathlean, J., Higgins, I., \& McMillan, M. (2009). Development and psychometric testing of the belongingness Scale - clinical placement experience: An international comparative study. Collegian, 16(3), 153-162. https://doi.org/10.1016/j.colegn.2009.04.004

Mays, N., \& Pope, C. (2000). Assessing quality in qualitative research. British Medical Journal, 320(50), 50-52. https://doi.org/10.1136/bmj.320.7226.50

McKenna, L., Gilmour, C., Biro, M., McIntyre, M., Bailey, C., Jones, J., Miles, M., Hall, H., \& McLelland, G. (2013). Undergraduate midwifery students' sense of belongingness in clinical practice. Nurse Education Today, 33(8), 880-883. https://doi.org/10.1016/j.nedt.2012.09.009

Meyer, S., \& Lunnay, B. (2013). The application of abductive and retroductive inference for the design and analysis of theory-driven sociological research. Sociological Research Online, 18(1), 86-96. https://doi.org/10.5153/sro.2819

Murray, S., \& Williamson, G. (2009). Managing capacity issues in clinical placements for pre-registration nurses. Journal of Clinical Nursing, 18(22), 3146-3154. https://doi.org/10.1111/j.13652702.2008.02693.x

National Nursing and Nursing Education Taskforce. (2006). A report on commonwealth funding to support the costs of clinical practicum for undergraduate nurses and midwives in Australia. Australian Health Ministers' Advisory Council. http://www.dhs.vic.gov.au/nnnet/publications.htm

Ntho, T., Pienaar, A., \& Sehularo L. (2020). Peer-mentees' challenges in an undergraduate peer-group clinical mentoring programme in a nursing education institution. Health SA Gesondheid, 25, 1-8. https://dx.doi.org/10.4102\%2Fhsag.v25i0.1435

Nursing \& Midwifery Council. (2018). Part 3: Standards for pre-registration nursing programmes. Nursing and Midwifery Council. https://www.nmc.org.uk/standards/standards-for-nurses/standardsfor-pre-registration-nursing-programmes/

Parpio, Y., Malik, S., Punjani, N., \& Farooq, S. (2013). Critical realism: Tenets and application in nursing. International Journal of Innovative Research \& Development, 2(11), 490-493. http://www.internationaljournalcorner.com/index.php/ijird_ojs/article/view/134048/93249

Perry, R., Press, M., Rohatinsky, N., Compton, R., \& Sedgwick, M. (2016). Pilot study: Nursing students' perceptions of the environment in two different clinical models. International Journal of Nursing Sciences, 3(3), 285-290. https://doi.org/10.1016/j.ijnss.2016.07.001 
Peters, K., Halcomb, E., \& McInnes, S. (2013). Clinical placements in general practice: Relationships between practice nurses and tertiary institutions. Nurse Education in Practice, 13(3), 186-191. https://doi.org/10.1016/j.nepr.2012.09.007

Potter-Dunlop, J. (2017). Lived experience of mutuality in a caring moment between the nurse and patient in an acute care setting. [Doctoral dissertation, University of Hawai' $i$ at Mānoa]. https://core. ac.uk/download/pdf/211329085.pdf

Price, L., Hastie, L., Duffy, K., Ness, V., \& McCallum, J. (2011). Supporting students in clinical practice: Pre-registration nursing students' views on the role of the lecturer. Nurse Education Today, 31(8), 780-784. https://doi.org/10.1016/j.nedt.2011.04.009

Priest, A. (2005). Student reps turn ideas into action. Nursing BC, 37(4), 21-25.

Ranse, K., \& Grealish, L. (2007). Nursing students' perceptions of learning in the clinical setting of the Dedicated Education Unit. Journal of Advanced Nursing, 58(2), 171-179. https://doi.org/10.1111/ j.1365-2648.2007.04220.x

Rasheed, S. (2017). The practicum in teacher education in the Maldives: Current practices, issues and future directions. [Doctoral dissertation, The Maldives National University]. http://saruna.mnu. edu.mv/jspui/bitstream/123456789/1699/1/Suneena\%20Rasheed.pdf

Reinke, N. (2018). The impact of timetable changes on student achievement and learning experiences. Nurse Education Today, 62, 137-142. https://doi.org/10.1016/j.nedt.2017.12.015

Rock, L., \& Ring, K. (2010). Evaluating the one-year block placement in field instruction. Revista de Asistenta Sociala, 9(4), 175-184. https://www.proquest.com/openview/065c5591e0609ac02a0e173 8bf06be9b/1?pq-origsite $=$ gscholar\&cbl $=105838$

Rohatinsky, N., Chachula, K., Compton, R., Sedgwick, M., Press, M., \& Lane, B. (2017). Nursing student preference for block versus nonblock clinical models. Journal of Nursing Education, 56(3), 152-157. https://doi.org/10.3928/01484834-20170222-06.

Rohatinsky, N., Chachula, K., Sedgwick, M., Press, M., Compton, R., \& Lane, B. (2018). Comparison of nursing student and instructor preferences for block and nonblock clinical models. Nurse Educator, 43(4), E1-E6. https://doi.org/10.1097/NNE.0000000000000458

Sala-Hamrick, K. (2019). "Please, sir, may I have some more?" How to get the most hours out of your clinical placement. Time to track, 5/6/19. http://blog.time2track.com/please-sir-may-i-have-somemore-how-to-get-the-most-hours-out-of-your-clinical-placement/

Shearer, J. B., \& Lasonen, J. (2018). Critical practice study of nursing evaluated by teachers. International Journal for Research in Vocational Education and Training, 5(2), 130-139. https://doi. org/10.13152/IJRVET.5.2.3

Sheepway, L., Lincoln, M., \& McAllister, S. (2014). Impact of placement type on the development of clinical competency in speech-language pathology students. International Journal of Language \& Communication Disorders, 49(2), 189-203. https://doi.org/10.1111/1460-6984.12059

Sheepway, L., Lincoln, M., \& Togher, L. (2011). An international study of clinical education practices in speech-language pathology. International Journal of Speech-Language Pathology, 13(2), 174-185. https://doi.org/10.3109/17549507.2011.491129.

Sherratt, L., Whitehead, B., Young, A., Collins, G., \& Brudrett, H. (2013). Using more healthcare areas for placements. Nursing Times, 109(25), 18-21.

Shiverick, D. (2012). Describing undergraduate placements. A full-time clinical practicum for undergraduates. In M. Ware \& R. Millard (Eds.), Handbook on student development. Advising, career development, and field placement (p. 238-240). Routledge. 
Strobbe, S., Hagerty, B., \& Boyd, C. (2012). Applying the nursing theory of human relatedness to alcoholism and recovery in Alcoholics Anonymous. Journal of Addictions Nursing, 23(4), 241-247. https:// doi.org/10.1097/jan.0b013e31826f67e8

Tastan, S., Iyigun, E., Ayhan, H., \& Hatipoglu, S. (2015). Experiences of Turkish undergraduate nursing students in the intensive care unit. Collegian, 22(10), 117-123. https://doi.org/10.1016/j.colegn.2013.12.003

Terry, K. (2013). The competency landscape: A critical realist exploration of the ways nurses understand and utilise competency standards [Doctoral disertation, University of Tasmania]. https://eprints.utas. edu.au/17166/

Theriot, M., Johnson, T., Mulvaney, M., \& Kretzschmar, J. (2006). Does slow and steady win the race? The impact of block versus concurrent field on BSW students' professional development and emotional well-being. Journal of Baccalaureate Social Work, 12(1), pp.203-217. https://doi.org/10.18084/10847219.12.1.203

Urwin, S., Stanley, R., Jones, M., Gallagher, A., Wainwright, P., \& Perkins, A. (2010). Understanding student nurse attrition: Learning from the literature. Nurse Education Today, 30(2), 202ᄀ-207. https:// doi.org/10.1016/j.nedt.2009.07.014

Uys, L., \& Gwele, N. (2005). Curriculum development in nursing. Process and innovations. Routledge.

Vanson, T., \& Bidey, T. (2019). Introduction of nursing associates. Year 2 evaluation report. Health Education England. https://allcatsrgrey.org.uk/wp/download/nursing/TNA-Year-2-Evaluation-Report_0.pdf

Vinales, J. (2015). The mentor as a role model and the importance of belongingness. British Journal of Nursing, 24(10), 532-535. https://doi.org/10.12968/bjon.2015.24.10.532

Warne, T., Johansson, U., Papastavrou, E., Tichelaar, E., Tomietto, M., Van den Bossche, K., Vizcaya Moreno, M., \& Saarikoski, M. (2010). An exploration of the clinical learning experience of nursing students in nine European countries. Nurse Education Today, 30(8), 809-815. https://doi.org/10.1016/j. nedt.2010.03.003

Wise, M. (2019). Reproducing injustice? The roles of social institutions and policy actors in the persistence of inequalities in Aboriginal and Torres Strait Islander life expectancy [Doctoral dissertation, Western Sydney University]. https://researchdirect.westernsydney.edu.au/islandora/object/uws:55884/

\section{Biographical Notes}

Phil Coleman is currently a Staff Tutor/Senior Lecturer in the Faculty of Wellbeing, Education and Language Studies at The Open University. Since joining this institution, he has undertaken various teaching and management roles and contributed to nursing, social work, and health and social care programmes. He is a Registered Mental Health Nurse, Nurse Tutor and a Fellow of the Society for Education and Training. Amongst other awards, he holds a Master of Education (Lifelong Learning), a BSc (Hons) Nursing Science, a Diploma in Nursing and is in the final stage of a part-time Doctorate of Education with Newcastle University. 